\title{
A Contrastive Study of Cohesion in Arabic and English Religious Discourse
}

\author{
Anas Huneety (Corresponding author) \\ Hashemite University, Jordan \\ E-mail: hneety@live.com \\ Bassil Mashaqba \\ Hashemite University, Jordan \\ E-mail: b_mashaqba@hu.edu.jo \\ Sabri. Shehadeh .Y. Al-Shboul \\ Hashemite University, Jordan \\ E-mail: sabri@hu.edu.jo \\ Abdallah Tayseer Alshdaifat \\ University of Jordan, Jordan \\ E-mail: a.shdaifat@ju.edu.jo
}

Received: 13-11-2016

Accepted: 05-01-2017

Advance Access Published: March 2017

Published: 01-05-2017

doi:10.7575/aiac.ijalel.v.6n.3p.116

URL: http://dx.doi.org/10.7575/aiac.ijalel.v.6n.3p.116

\begin{abstract}
This paper aims to analyze the use of cohesion in Arabic and English religious spoken texts. Twelve texts, delivered by some of the most eloquent Imams, were analyzed in light of the model proposed by Halliday \& Hasan (1976). The study reveals that lexical cohesion is the most dominant type of cohesion in Arabic religious discourse, whereas it is grammatical cohesion which dominates English religious discourse. Although both languages prefer the use of reference, conjunctions and lexical repetition, Arabic uses lexical repetition, collocation and personal pronouns more often than English. A major contribution of the present study is that it captures new cohesive devises employed in Arabic religious discourse other than proposed by Halliday \& Hasan (1976): rhyming patterns and parallelism.
\end{abstract}

Keywords: Discourse analysis, cohesion, contrastive research

\section{Introduction and Literature Review}

Text linguistics approaches language as discourse rather than sentences in isolation (De Beaugrande \& Dressler 1981). Gray (1976) shows that textual perspective is required to figure out some types of sentences, e.g., anaphora and deixis that cannot be interpreted but be examined in relation to their discourse or context. A text is treated as a semantic unit defined in terms of meaning rather than length (Halliday \& Hasan 1976). The term text is used instead of discourse to refer to any passage, spoken or written, prose or verse, of whatever length and that works as one unit (ibid). Sentences combine together to form larger units of language that construct a unified whole. De Beaugrande (1981) sees that the functional unity of the text requires seven standards of textuality: cohesion, coherence, acceptability, informativity, intentionality, situationality, and intertextuality. If any of these standards is missed, these sentences fail to fulfil a communicative function and therefore deemed a non-text (ibid). Stubbs (2002) shows that sentences cannot construct a text if the relation between them is lacking meaning. Where each text type utilizes a set of distinguishing cohesive ties that make it stand out from other text types (Halliday \& Hasan 1976; Huneety 2009), the present paper aims to point out the similarities and differences between spoken religious texts in Arabic and English in terms of the use of cohesive devices. Adopting Halliday \& Hasan's model (1976), this paper aims to show if religious spoken discourse, in Arabic and English, utilizes any cohesive device other than those proposed by Halliday \& Hasan (1976).

The unity of the text has always been associated with some linguistic markers called cohesive ties (Halliday \& Hasan 1976; De Beaugrande \& Dressler 1981). In Halliday \& Hassan's model, the set of cohesive devices are: reference, ellipsis, substitution, conjunctions, and lexical cohesion. These devices create relations of meaning among different components of the text and thus leading to the continuity of the text. Cohesion is, however, deemed insufficient for the creation and identification of text (Brown \& Yule 1983), and insufficient for the unity of the text (De Beaugrande 1981). 
Different definitions have been proposed to the term cohesion. Cohesion is a semantic relation that exists between linguistic and extralinguistic entities in text and situation (Halliday \& Hassan 1980). It lends continuity to the text by making relations of meaning between the different parts of the text. VanDijk (1992) reports that cohesion refers to the principles of connectivity that link the text and force co-interpretation. De Beaugrande \& Dressler (1981) demonstrate that cohesion shows how text surface structure elements, such as phrases, sentences, and clauses are linked through a sequence. Johnstone (2002: 101-103) defines cohesion as the property that connects sentences to other sentences within the same text. She demonstrates the existence of a set of internal cohesive markers including reference, conjunctions and substitution that help text receivers relate the different portions of the text as to keep them unified (ibid). Halliday (1994: 309) defines cohesion as 'the set of resources for constructing relations in discourse which transcend grammatical structure'. It is viewed by Leech (2001) as a way of connecting ideas to linguistic arrangements to form a text. Graesser et al (2004: 193) define cohesion as the use of explicit features, words, phrases or sentences that help the reader interpret the substantive ideas in the text and link them with other ideas in the text as well as with higher level units, e.g., topics, themes. It refers to the set of cohesive markers that point out meaningful relations among the different parts of the text (Olshtain \& Haskel-Shaham: 2012). Paltridge (2012) maintains that cohesion patterns, i.e. reference, substitution, ellipsis, conjunction and lexical cohesion, express the integration of grammar and discourse in language. It seems that all above definitions revolve around one idea: cohesion is an essential component of textness which refers to the ways of giving texture to a piece of text.

Halliday \& Hassan (1976) have produced the most comprehensive taxonomy of cohesive devices. Under this taxonomy, cohesion is subdivided into two broad categories: grammatical and lexical. Grammatical cohesion concerns the grammatical features of a sentence while lexical cohesion deals with the different vocabulary links (Carter 2008). The grammatical category refers to the structural content and is divided into reference, substitution, ellipsis and conjunction. Partridge (2012: 117) demonstrates that lexical cohesion refers to 'the relationships in meaning between lexical items in a text and, in particular, content words and the relation between them'. It deals with the ways where lexical items relate to each other and to other cohesive devices that ensure texual continuity (Flowerdew \& Mahlberg 2009:1). Lexical devices are divided into reiteration, collocation and sense relations (such as synonymy, antonymy, and hyponymy) (Rasheed \& Abid 2016). For Halliday \& Hasan (1976), reference is a universal linguistic phenomenon, where each language makes use of some referential ties to link phrases, clauses and sentences in a given text. Similarly, Valeika \& Verikate (2010) show that reference is a linguistic mechanism that relates one element of the text with another. They call the referring expression as the antecedent and the subsequent one as the anaphor. Johnstone (2002) argues that a referential tie is created when the interpretation of a dummy word is to be sought somewhere in the text or situation; thus, to interpret an item in one sentence, readers will have to refer to another part of some other sentence. Where pronouns are probably the main resource speakers/writers have for referring (Johnstone 2002: 118), reference falls into two categories: exophoric and endophoric. Endophoric reference is defined as the textual relationships between elements of a piece of discourse, and where the interpretation of the referent lies in the text itself (Halliday \& Hasan 1976; Yule \& Brown 1983, Johnstone 2002; Halliday 2004). According to Halliday (2004: 552), exophoric reference means that 'the identity presumed by the reference item is recoverable from the environment of the text'. It refers to the relationship between the text and its surrounding context and thus, readers have to look outside the text for true interpretation of the referent (Halliday \& Hasan 1976; Brown \& Yule 1983; Johnstone 2002). In other words, exophoric reference 'directs the receiver out of the text and into an assumed shared world' McCarthy (1991: 41).

Endophoric reference is accordingly classified in terms of direction into anaphoric, pointing back to a preceding item, and cataphoric, pointing forwards to a following item (Halliday \& Hasan 1976, Johnstone 2002; Halliday 2004). Only endophoric reference is cohesive, according to Halliday \& Hasan (1976), because it allows a linkage between parts of the same text, unlike exophoric reference which has no role lending cohesion to the text. Three types of reference are further introduced: personal, comparative and demonstrative (for more details see Halliday \& Hasan 1976:38-86).

Substitution refers to the grammatical aspect of cohesion whereby an item in one sentence substitutes for material somewhere in the text in the same grammatical slot (Johnstone 2002). It is the grammatical case of reference to a previously mentioned element (Halliday \& Hasan 1976). The major goal of substitution is to avoid repetition of unnecessary items (Vujević 2012). The main distinction between substitution and reference lies in the fact that 'reference is a relation on the semantic level, whereas substitution is a relation on the lexicogrammatical level, the level of grammar and vocabulary, or linguistic forrm' (Halliday \& Hasan -1976: 89). Three types of substitution are distinguished by Halliday \& Hasan (1976): nominal, verbal and clausal. Nominal substitution is mostly introduced by items that replace heads of nominal groups; the most typical instances are 'one', 'ones', and 'some' (bidi). In verbal substitution, the verb 'do' replaces a verb phrase, creating a linkage between two elements of a piece of discourse. Thus, the interpretation of 'do' is dependent on another item in the text itself, creating a cohesive tie that lends continuity to the text (ibid). Where the most typical instances of clausal substitution are 'so' and 'not', the cohesion of such a type lies in the fact that the interpretation of both items is retrievable by recourse to a previous piece of the text (Johnstone 2002).

Ellipsis is an important aspect of grammatical cohesion whereby an item is omitted and readers have to go somewhere in the text to fill in the blank (Halliday \& Hasan 1976:143). It involves deliberate deletion of words, phrases; yet clarity is maintained (cf. Kennedy 2003, Harmer 2004: 24). Such deliberate deletion of lexical items creates a cohesive tie that cements the texture of the text. Although ellipsis is relatively related to substitution, in the case of ellipsis, an item is omitted rather than being replaced (Halliday \& Hasan 1976, Harmer 2004). It is viewed by Halliday \& Hasan (1976: 142 ) as 'substitution by zero'. Similar to substitution, there are three types of ellipsis: nominal, verbal and clausal. 
The fourth grammatical category is conjunctions which relate what is to be said to what has been said before using markers like 'and', 'or', 'yet', 'therefore', 'because', ... etc (Halliday \& Hasan 1976). Conjunctive elements are not cohesive by themselves, but by virtue of the meaning they denote. While other grammatical markers of cohesion are focusing attention on the semantic relation, conjunctives are realized 'thorough the function they have each other linguistic elements that occur in succession but are not related by other, structural means' (Halliday \& Hasan 1976: 227). Basically, there are several types of conjunctives: additive, adversative, causal, and temporal (Ghzalah 2001). Additive conjunctives work cohesively by creating a relation of addition between two elements and they are usually signalled by 'and', 'in addition', 'moreover', 'further', etc, (Wardat 2010). Adversative conjunctives denote the contrary to what has been said using some conjunctives such as 'yet', 'though', 'although', 'despite', 'in spite of', etc (Ghzalah 2001). Causal conjunctives denote result, reason and purpose and they are marked via 'so', 'since', 'therefore', 'as a result', etc. (ibid). Temporal conjunctives express a sequence of time, e.g. 'then', 'next', 'until', 'at this time' (ibid)

Lexical cohesion is created by items that connect several parts of the text together by providing semantic relations between them. It refers to the cohesive effect created via the selection of vocabulary (Halliday \& Hasan 1976). Lexical cohesion contributes to the meaning by creating different groups of related words that run through the text (ibid). Hoey (1991) claims that lexical cohesion is the most important type of cohesion because it can create a network of connections among different components of the text. Basically, this study examines lexical cohesion under three headings: reiteration, collocation and sense relations. Such devices function as cohesive ties that cement the cohesiveness of the text.

Reiteration is a characteristic that exists in most of the world languages to serve different purposes, e.g. emphatic, rhetorical (Ali \& Abdel-Fattah 2006). It either involves the exact repetition of a lexical term or the use of a synonymy of some kind in the context of reference (Halliday \& Hasan 1976). Repetition includes 'words which are inflected for tense or number and words which are derived from particular items' (Paltridge 2012: 117). Reiteration in this study is limited to the exact repetition of a lexical term or one of its inflections. The cohesion of such kind of repetition lies in creating semantic relations between different terms in the same text. Collocation is a syntagmatic relation of the cooccurrences that hold between lexical items, so that when one item in discourse is mentioned, it is accompanied by another (Firth 1957). Collocates refer to words which could be used in the same context or that contribute to the same area of meaning (Kennedy 2003). The cohesion of such kind lies in the predictability of the co-occurences of lexical items, i.e., if one word occurs, the other word is most likely to occur in vicinity (Halliday \& Hasan 1976). This supports the semantic unity of the whole text. The last lexical category refers to sense relations which comprise synonymy, hyponymy and antonymy. The use of any of these relations creates semantic relations between different items which contribute to the unity of the text.

Longacre \& Levinshon (1978) discuss the different devices that contribute to the unity of the text, including the role of tense and aspect, deictics, lexical paraphrase, back reference, and summary and preview. They emphasize on the role that tense and aspect play in providing readers with the text type, providing cohesion throughout the text and encoding the type of discourse used. On the lexical aspect, the use of any sense relation (e.g., synonymy, antonymy, and hyponymy) creates cohesive ties that lend unity to the text. Further, repetition of predicates and vocabulary hierarchically ordered from generic to specific constitute paraphrase relations with cohesive functions. They also maintain that summary and preview lend unity to the text (ibid). Summary refers to the type of paraphrase that makes use of generic predicates and substitutes, whereas preview gives in one part of a discourse what will follow later (ibid).

Doubtful about Halliday \& Hasan's model of cohesion, Brown \& Yule (1983) argue against treating texture as an essential element to the identification of the text. They maintain that readers will assume semantic relations and interpret sentences in light of the previous ones when encountering a text.

Much of the literature shows that different text types cohere differently as well as each language tends to utilize a range of cohesive devices that facilitate text processing (Rashdan 2007; Huneety 2009; Wardat 2010). For example, Arabic tends to cohere mostly using pronominal reference, conjunctive elements, lexical repetition and parallelism (Rashdan 2007; Huneety 2010; Aziz 2012). Additionally, Arabic uses the same themes successively while English tends to use semantically related themes (Aziz 2012). In his examination of cohesion in Arabic religious and literary texts, Huneety (2009) demonstrates that where both religious and literary texts prefer the use of reference, conjunctions and lexical repetition, religious discourse tends to utilize rhymes and topic to connect the different parts of the text. Given this, no single study has been devoted to pointing out the similarities and differences between religious discourse in Arabic and English, and capturing any new cohesive devices employed other than those employed by Halliday \& Hasan (1976).

Below is an overview of the methodology used in this study followed by an examination of the cohesiveness of selected religious texts from English and Arabic in light of the model proposed by Halliday \& Hassan (1976).

\section{Methodology and Research Questions}

This research aims to fill in a gap in the field of contrastive textology by comparing selected religious spoken discourse from Arabic and English in terms of cohesion. For maximal comparability, twelve religious speeches, six in Arabic and six in English, have been analysed in terms of the use of cohesive devices. All speeches were delivered by some of the most famous, eloquent imams in the Islamic: Abd Al-Rahman Sudais, Imam of Mecca, and Muhammad Estes. After collecting the data, the researchers analyse the cohesive ties involved in them and categorize them according to the type 
of cohesion. The method of analysis largely draws on Halliday \& Hassan's model (1976). Basically, the study aims to answer the following questions:

1- What are the cohesive devices employed in Arabic and English religious texts?

2- What are the similarities and differences between Arabic and English religious texts in terms of the use of cohesive devices?

3- To what extent does cohesion in Arabic and English religious texts correspond with the categories of cohesion employed by Halliday \& Hasan (1976)?

Section one presents an overview of cohesion and reviews literature on Arabic and English cohesion. The methodology along with the research questions are discussed in section two. Data analysis is then given, providing a detailed account of the cohesive devices used in religious discourse in each language. The study concludes with a summary of the results on the use of cohesive devices manipulated in both languages, and offers suggestions for further studies.

\section{Result and Discussion}

Analyzing religious discourse in Arabic and English reveals the use of a variety of cohesive devices used to provide texture and to clarify relationships among them. Table (1) gives a summary of the frequency of the occurrences of cohesive ties, grammatical and lexical, in Arabic and English religious speeches.

Table 1. Summary of the occurrences of cohesive devices in religious texts in Arabic and English

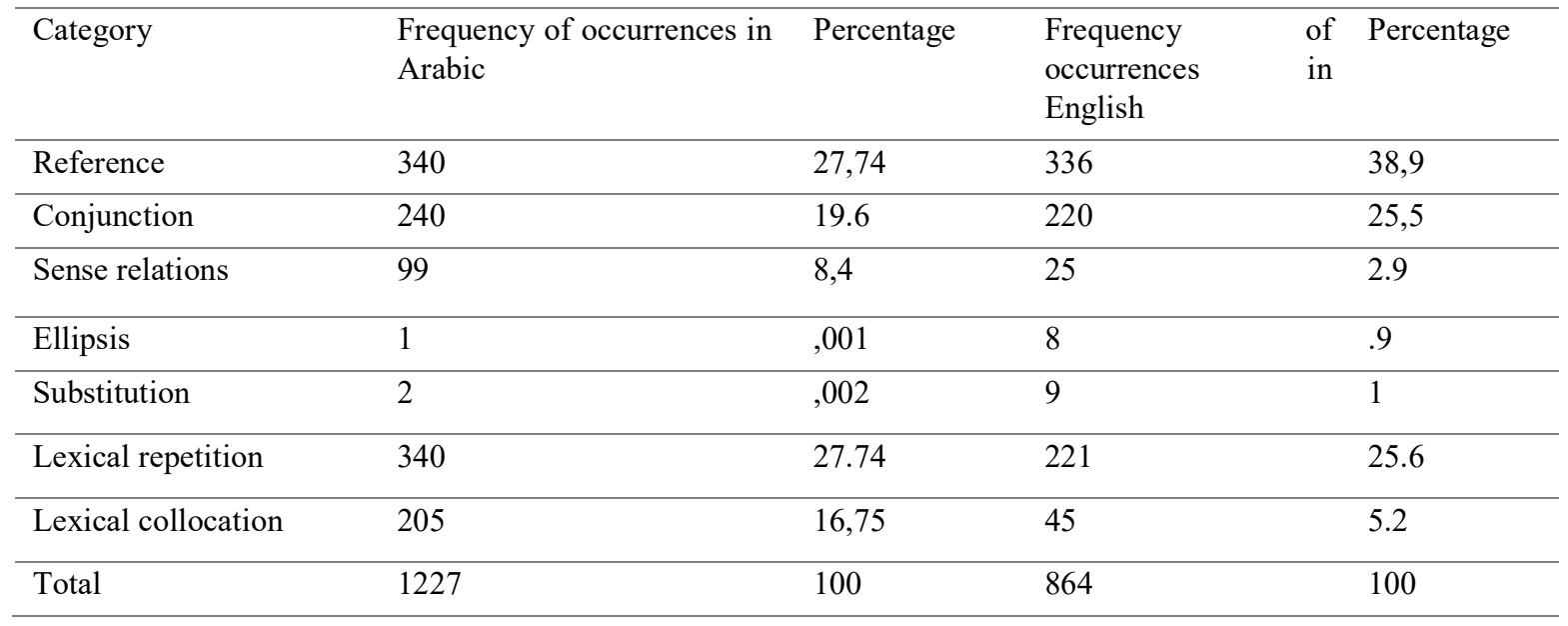

As seen in Table (1), there are 1227 cohesive ties in the six Arabic speeches; of which 644 ties are lexical (52.4\%) and 583 are grammatical $(47.6 \%)$. In terms of lexical cohesion, lexical repetition is the most frequent device creating 340 lexical ties that contribute to $27.74 \%$ of the cohesiveness of Arabic religious speeches. The high rate of lexical repetition might be partly attributed to the notion that Arabic is generally classified as a productive derivational language where many words are derived from the same root. This creates a lexical tie between many items that belong to the same root and thus helps keep the text unified. For instance, the root ?-m-n generates a number of related derivatives, e.g. mu?min 'believer', Pìmān 'faith, yu?min 'he believes'. Imams repeat some phrases to put more focus on an issue. For instance, the phrase al-hamdu li-l-lah 'praise be to Allah', has been repeated fifteen times in one of Sudais speeches in the context where he was relating the multiple bounties of Allah on human beings. Lexical collocation contributes essentially to the unity of Arabic religious texts with a frequency average of $16.75 \%$ (205 occurrences). Where sense relations create 99 cohesive ties (an overall 8.6\% in the selected Arabic speeches), the majority of these ties are antonymys ( 82 occurrences), followed by synonymy (11 ties) and then hyponymy (6 ties).

On the grammatical aspect, reference is the most dominant cohesive aspect that contributes to around $27.74 \%$ of the cohesiveness of Arabic religious speeches. The cohesion of reference lies in the fact that the interpretation of a dummy word is dependent on another item in the text itself, creating a cohesive tie that cements the unity of the text. As reference is divided into personal, demonstrative, and comparative (Halliday \& Hasan 1976), our analysis of data, see Table (2), shows that personal reference is the most effective device of all reference types, having an average of 95,2 (325 occurrences). Both demonstrative and comparative types have a low average compared to personal reference, i.e., both types are responsible for $4.8 \%$ of the cohesiveness of the selected texts. Table (2) summarizes the frequency of reference in Arabic religious speeches.

Table 2. Frequency of reference in Arabic religious speeches

\begin{tabular}{lll}
\hline Reference type & Frequency & Percentage \\
\hline personal & 325 & 95.2 \\
\hline demonstrative & 10 & 2.9 \\
\hline comparative & 5 & 1.9 \\
\hline
\end{tabular}


Conjunctions comprise $19.6 \%$ of the overall cohesive ties in the selected Arabic speeches. Additive conjunctives have been dominantly used, with a frequency average of $86 \%$ (207 occurrences), followed by cause and effect conjunctives with an average of $7.5 \%$ (18 occurrences), temporal conjunctives with a frequency average of 4.5 (11 occurrences), and finally comes adversative conjunctives with a rate of $2 \%$ (4 occurrences). Table (3) summarizes the frequency of conjunctive elements in Arabic religious speeches.

Table 3. frequency of conjunctive elements in Arabic religious speeches

\begin{tabular}{lll}
\hline Type & Frequency & Percentage \\
\hline Additive & 207 & $86 \%$ \\
\hline Cause and effect & 18 & $7.5 \%$ \\
\hline Temporal & 11 & 4.5 \\
\hline Adversative & 4 & $2 \%$ \\
\hline
\end{tabular}

Both substitution and ellipsis have no role in the cohesiveness of Arabic religious speeches and the reason for this is that Imams are trying to avoid ambiguity and misunderstanding, taking into consideration the low level of education of some attendees.

English religious speeches, by contrast, show considerable differences to Arabic ones. 864 cohesive ties have been utilized in the six English speeches, of which there are 573 grammatical ties and 291 are lexical. Among the 864 ties, reference is the most frequent device contributing to around $38.9 \%$ of the total ties used in the six speeches $(336$ occurrences). Among the 336 referential ties, personal reference is the most common with an average of 245 occurrences $(72.9 \%)$, followed by demonstrative reference of 61 occurrences $(18.2 \%)$ and comparative reference contributing of 30 referential ties $(8.9 \%)$. Conjunctions are shown to play a very significant role in the cohesiveness of English religious speeches. They are responsible for $25.5 \%$ of the percentage of cohesive devices in the selected speeches. Additive conjunctions have been used dominantly with a frequency average of $64.5 \%$, followed by temporal conjunctives $(26.3 \%)$, cause and effect $(7.5 \%)$, and then adversative $(1.7 \%)$. Ellipsis and substitution play a minor role in the cohesiveness of English religious texts, i.e. both comprise around 2\% (17 occurrences).

On the lexical aspect, lexical reiteration is the most employed type of lexical cohesion utilized with a frequency average of $25.6 \%$ (221 occurrences), followed by collocations $5 \%$ (45 occurrences), and then sense relations $3 \%$ ( 25 occurrences).

After a careful examination of the results, we come up with the following conclusions:

First, examining both texts in terms of the use of cohesive devices, we find that cohesion plays a fundamental role in creating and understanding discourse. This satisfies Cook's (1994) view of textual cohesion as a predictor of coherence.

Second, it has also been observed that lexical cohesion is the dominant manifestation of cohesion in English religious speeches, with a frequency average of $66.3 \%$ versus $33.7 \%$ of lexical cohesion. By contrast, lexical cohesion contributes more to the cohesiveness of Arabic religious speeches, creating 644 ties that form (52.4\%) of the cohesiveness of Arabic speeches versus 583 grammatical ties (47.6\%).

Third, sense relations are widely utilized in Arabic speeches as devices to link different items together with a frequency average of $8.6 \%$ (99 occurrences), whereas their usage is not as frequents in English as in Arabic. In English they contribute to $3 \%$ of the cohesiveness of these speeches. The vast majority of sense relation ties in Arabic are antonymys ( 82 occurrences), while both synonyms and hyponyms contribute to 11 and 6 ties respectively. However, sense relation ties are less frequent in English texts (25 occurrences).

Third, both Arabic and English religious speeches widely use reference, conjunctions and lexical cohesion as tools to link the different parts of the text and give them texture. The wide use of reference might be attributed to the fact that many verbs tend to take two nouns: one functions as its subject and the other as its object. Further, Arabic tends to avoid the repetition of a lexical item except for rhetorical purposes; thus, when a noun is repeated for a second time, it is replaced by a pronoun. Personal pronouns come on the top of most frequently used pronouns, with an overall average of $98 \%$. Where Arabic makes little use of comparative reference, English religious speeches use it three times more frequently than that of Arabic (45 occurrences in English versus 14 in Arabic).

Fourth, lexical repetition is more frequently in Arabic speeches than in English. Thus, where the six Arabic speeches have 341 occurrences of lexical repetition, English speeches have less half that amount, i.e. 181. This is in line with alKafaji (2005) who shows that lexical recurrence is a characteristic of Arabic discourse. Further, repetition is widely used as a rhetorical device that plays a major role in creating emphasis on certain points, attitudes or views.

Fifth, ellipsis and substitution play a marginal role in the cohesiveness of Arabic religious speeches, representing less than $1 \%$ (three occurrences together), while English makes more use of both devices, particularly ellipsis with an average of $1.9 \%$ (17 occurrences). The reason might be that Imams are more considerate of their audience in Arabic and thus they are trying to avoid ambiguity and misunderstanding. 
Sixth, conjunctions perform a central role in the cohesiveness of both Arabic and English religious speeches, ranking third in Arabic with an average of 19.5 and second in English 25.5\%. Where additive conjunctives are most frequent in both languages, the use of temporal markers in English speeches is five times more frequent than that of Arabic (26.5\% in English versus 4.5\% in Arabic).

Collocations refer to habitual association of lexical items. The study shows that Arabic religious speeches are abundant in collocations that contribute to $27 \%$ of the cohesiveness of the examined speeches. English speeches, by contrast, exhibit fewer examples of collocations, only 40 occurrences that contribute to only $5 \%$ of the cohesiveness of Arabic religious speeches.

The present paper has attempted to answer the question if there are any cohesive devices utilized in Arabic and English religious speeches other than those employed by Halliday \& Hasan (1976). After examining our collected data, we find two other cohesive devices functioning cohesively: rhyming patterns, known in Arabic as $s a j{ }^{c}$, and parallisim. Rhyming patterns refer to the repetition of similar sounds, sometimes the same sound, in two or more utterances, creating lexical ties that cement the cohesiveness of the text. For illustration, consider the following example:

الحمد الله الملك الجليل، المنزَّه عن النظير والعديل، المنعِم بقبول القِلِل، المتكرِّم بإعطاء الجزيل، تقدَّ عمَّا يقول أهل التعطيل، وتعالى عمَّا بعتقد أهل التمثيلِ

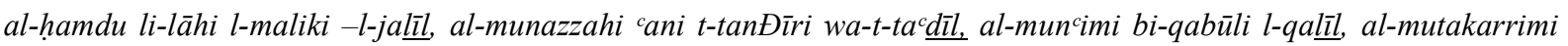
bi-Picțāei l-jazīl, taqaddasa 'ammā yaqūlu Pahlu t-tacțill

In the above piece of speech, the repetition of the rhyme $-\bar{l} l$ at the end of each utterance creates six lexical ties that connect the six utterances together and this supports the unity of the speech.

According to Cook (1989:15), parallelism is 'a device which suggests a connection, simply because the form of one sentence or clause repeats the form of another'. It refers to the repetition of a structure in different sentences, phrases to reflect similarity in meaning (De Beaugrande 1984). It involves using items of similar importance in similar constructions. Parallesim technique is so common in poetry advertisements, and speeches to have a powerful 'emotional effect', Cook (1989:15). The parallelism device has been used effectively to give texture to Arabic and English religious speeches. The cohesive value of parallelism lies in using parallel structures create strong relations between them and this leading to the unity of the text. For illustration, consider the following example:

$$
\text { اللهم أنت غيّاثنا فبك نغوثر, وأنت ملاذنا فبك نلوذ, و أنت عياذنا فبك نعوذ }
$$

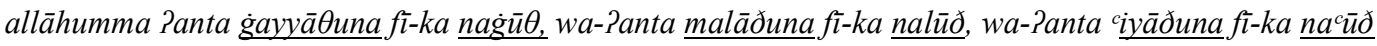

'We are seeking refugee from Allah'

The above is an instance of synonymous parallelism where the three underlined structures convey the same message: seeking refugee from Allah using the same structure.

\section{Conclusion}

This paper provides a comparative study of the use of cohesion in Arabic and English via selected religious spoken texts elicited from the ceremonies of the most influential preachers (Imams). The analysis of 12 religious speeches, six in Arabic and six in English, reveals substantive differences between the two languages in terms of the use of cohesive devices. The study finds out that lexical cohesion is the dominant type of cohesion in Arabic religious discourse and it tends to use lexical repetition, collocation, reference and conjunctions. English religious discourse is significantly dominated by grammatical aspects of cohesion and coherence most often using reference, lexical repetition and then conjunctions. The analysis reveals two other interesting powerful devices that mark cohesion in Arabic discourse: rhyming patterns and parallelism. The study recommends conducting some research to find the most frequent cohesive devices in folklore songs.

\section{References}

Ali, M., \& Ahmed A.. (2006). Word repetition in the Qur'an: translating form or meaning?. Journal of King Saud University, 19, 17-34

Al-Kafaji, R. (2005). Variation and recurrence in the lexical chains of Arabic and English texts. Poznan Studies in Contemporary Linguistics, 40, 5-25.

Aziz, R. (2012). Parallism as a cohesive device in English and Arabic prayers: Contrastive Analysis. Al Austaz Journal, 20, 353-371.

Brown, G. \& Yule, G. (1983). Discourse analysis. New York: Cambridge University.

Carter, R. (2008). Working with texts: A core introduction to language analysis. London: Routledge.

Cook, G. (1989). Discourse. Oxford: OUP.

Cook, G. (1994). Discourse and literature. Oxford: Oxford University Press.

De Beaugrande, R. (1980). Text, discourse, and process: Toward a multidisciplinary science of texts. Norwood, N.J.: ABLEX Pub. Corp.

De Beaugrande, R. \& Dressler, W. (1981). Introduction to text linguistics. London: Longman.

De Beaugrande, R. (1984). Text production-toward a science of composition. O. F. (ed.): Roy University of Florida, 11. 
Firth, J. (1957). Papers in Linguistics (1934-1951). Oxford: Oxford University Press.

Flowerdew, J., \& Mahlberg, M. (Eds.). (2009). Lexical Cohesion and Corpus Linguistics. Amsterdam, NLD: John Benjamins Publishing Company.

Gary, N. (1976). A discourse analysis of certain root transformations in English. Reproduced by the Indiana University Linguistics Club: Bloomington, Indiana.

Gazallah, H. (2001). Cohesion in translation: The importance of sentence connectors (English-Arabic).Turjuman,10(2), 73-78.

Graesser, A., McNamara, D. S., Louwerse, M. M., \& Cai, Z. (2004). Coh-Metrix: Analysis of text on cohesion and language. Behavior Research Methods, Instruments, \& Computers, 36(2): 193-202.

Halliday, M. A. (1994). Functional grammar. London: Edward Arnold.

Halliday M. A. K. (2004). An Introduction to functional grammar. London: Oxford University Press Inc.

Halliday, M. A.K. \& Hassan, R. (1976). Cohesion in English. New York: Longman.

Harmer, J. (2004). How to teach writing. Pearson Educated Limited.

Hoey, M. (1991). Patterns of lexis in text. Oxford: Oxford University Press.

Huneety, A. (2009). Cohesion in religious and literary Arabic texts. M.A. Thesis, Yarmouk University.

Johnstone, B. (2002). Discourse analysis. Oxford: Blackwell publishers.

Kennedy, C. (2003). Ellipsis and syntactic representation. In Schwabe, K, \& Winkler, K, (eds). The Interfaces: Deriving and Interpreting Omitted Structures:29-53. Amsterdam: John Benjamins.

Longacre, R. E., \& Levinsohn, S. (1978). Field analysis of discourse. Current trends in textlinguistics, $103,22$.

McCarthy, M. (1991). Discourse analysis for language teachers. Cambridge: CUP.

Olshtain, E. \& Haskel-Shaham, I. (2012). A discourse approach to second language teaching. In I. Haskel et al. (Eds.), Mizimrat Halashon - Essays in Language Education: 366-387. Jerusalem: The Ministry of Education.

Paltridge, B. (2012). Discourse analysis: An introduction, 2nd (ed.). London: Bloomsbury Publishing.

Rashdan, I. (2007). Cohesion in the Holy Quran. M.A. Thesis, Yarmouk University.

Rasheed, S., \& Abid, A. (2016). A Comparative study of lexical cohesive devices used by L1 and L2 Urdu speakers' Language in India 16 (4): 190-217. .

Stubbs, M. (2002). Two quantitative methods of studying phraseology in English. International Journal of Corpus Linguistics, 7(2): 215-44.

Valeika, L., Verikaite, D. (2010). An Introduction course in linguistic pragmatics. Vilnius: Vilnius University Press.

Van Dijk, T. (1992). Discourse and the denial of racism. Discourse \& Society, 3(1), 87-118.

Vujević, V. M. (2012). Ellipsis and substitution as cohesive devices. http://www.ffuis.edu.ba/media/publikacije/radovi/2012/05/28/31_Vera_Vujevic.pdf

Wardat, A. (2010). Cohesion and coherence in his majesty king Abdullah II's English and Arabic speeches. M.A. Thesis, Yarmouk University. 